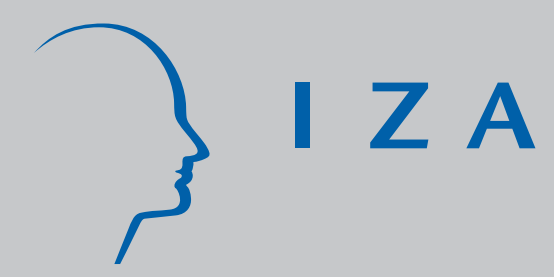

IZA DP No. 2689

An Analysis of Hospital Efficiency and Productivity
Growth Using the Luenberger Productivity Indicator

Carlos Pestana Barros

António Gomes de Menezes

J osé Cabral Vieira

Nicolas Peypoch

Bernardin Solonandrasana

March 2007 


\title{
An Analysis of Hospital Efficiency and Productivity Growth Using the Luenberger Productivity Indicator
}

\author{
Carlos Pestana Barros \\ ISEG, Technical University of Lisbon \\ António Gomes de Menezes \\ University of the Azores and CEEApIA \\ José Cabral Vieira \\ University of the Azores, CEEApIA and IZA \\ Nicolas Peypoch \\ Université de Perpignan \\ Bernardin Solonandrasana \\ Université de Perpignan
}

\author{
Discussion Paper No. 2689 \\ March 2007
}

\author{
IZA \\ P.O. Box 7240 \\ 53072 Bonn \\ Germany \\ Phone: +49-228-3894-0 \\ Fax: +49-228-3894-180 \\ E-mail: iza@iza.org
}

\begin{abstract}
Any opinions expressed here are those of the author(s) and not those of the institute. Research disseminated by IZA may include views on policy, but the institute itself takes no institutional policy positions.
\end{abstract}

The Institute for the Study of Labor (IZA) in Bonn is a local and virtual international research center and a place of communication between science, politics and business. IZA is an independent nonprofit company supported by Deutsche Post World Net. The center is associated with the University of Bonn and offers a stimulating research environment through its research networks, research support, and visitors and doctoral programs. IZA engages in (i) original and internationally competitive research in all fields of labor economics, (ii) development of policy concepts, and (iii) dissemination of research results and concepts to the interested public.

IZA Discussion Papers often represent preliminary work and are circulated to encourage discussion. Citation of such a paper should account for its provisional character. A revised version may be available directly from the author. 


\section{ABSTRACT}

\section{An Analysis of Hospital Efficiency and Productivity Growth Using the Luenberger Productivity Indicator}

We analyze the efficiency and productivity growth of a representative sample of Portuguese hospitals from 1997 to 2004, using an innovative approach by employing the directional distance function and the Luenberger productivity indicator. The primary advantage of our approach is that both input contractions and output expansions are considered. Our model generates a productivity indicator that is decomposed into the usual constituents of productivity growth: technological change and efficiency change. The results show that, on average, Portuguese hospitals did not experience productivity growth during the period analyzed. In addition, the incidence of positive productivity growth across Portuguese hospitals was remarkably low.

JEL Classification: I11, I18, L5

Keywords: hospitals, Luenberger productivity indicator, efficiency, technological change, productivity

Corresponding author:

António Gomes de Menezes

University of the Azores

Rua da Mãe de Deus

9501-801 Ponta Delgada

Portugal

E-mail: menezesa@notes.uac.pt 


\section{Introduction}

The aim of this paper is to analyze hospital efficiency and productivity growth. For that, we employ the Luenberger productivity indicator to study a representative sample of Portuguese hospitals in the period 1997-2004. Whereas productivity may be estimated by parametric techniques, the most popular approach employs non-parametric methods - data envelopment analysis (DEA) and the Malmquist productivity index. Yet, differences exist between productivity measures based on ratios (indices) and differences (indicators). Since Malmquist indices often overestimate productivity change, recently, difference-based productivity indicators, such as the Luenberger productivity indicator, have been introduced [1]. In this paper, we innovate in the field of hospital performance studies with an application of the directional distance function and of the Luenberger productivity indicator to the analysis of hospital efficiency and productivity growth. Quite interestingly, the Luenberger productivity indicator is decomposed into the familiar constituents of productivity growth: technological change and efficiency change, and, hence, our analysis sheds light on both of these interesting dimensions of productivity growth.

The hospital sector constitutes an important ground for productivity studies. Hospitals absorb a large share of public health expenditures. As the hospital sector is highly regulated, there is an obvious need for assessing its performance (see [2] for an illuminating discussion on the need to analyze the efficiency and productivity of health care organizations).In Portugal, the ratio of health expenditures to GDP has increased from $8.4 \%$ in 1998 to $9.6 \%$ in 2003, exceeding the average values in the EU, of 8.2\% in 1998 and 8.8\% in 2003. Confronted with an endemic public deficit, Portugal is being forced by the European Maastricht Treaty to shrink its public expenditures. As hospitals command about $50 \%$ of public health expenditures, there is much warranted discussion in Portugal on how to reform the hospital sector. However, scant research has been conducted on Portuguese hospitals [3-5]. More to the point, and to be short, these studies overlooked productivity growth issues, unlike this paper. Present reforms include the closing of small, regional health facilities as well as the construction of new hospitals. Reforms also include the implementation of restrictions on prescription drug subsidies, doctors' wages and hours worked, organizational changes, such as defining some public hospitals as publicly-owned companies. Hence, policymakers need to establish whether a given (de)regulation model achieves its intended effects on productivity. For that, some formal assessment of hospital productivity growth is in order. This paper contributes to fill this gap in the Portuguese case and innovates in the field of hospital performance studies with the introduction of the Luenberger productivity indicator.

The remainder of this paper is organized as follows. Section 2 reviews the literature. Section 3 details the methodology. Section 4 presents the data and the results. Section 5 concludes. 


\section{Literature Review}

Hospital efficiency analysis is an important issue within the field of health economics. There are two contemporary approaches to measure hospital efficiency: the parametric approach and the nonparametric approach. Particularly important to the present paper are the studies that have focused on national markets. Among the studies that have employed non-parametric frontier techniques, several approaches are observed. First and foremost, we find the traditional DEA approach, which identifies technical efficiency. This approach was adopted by the early literature [6-11]. Second, we find the studies that focus on the decomposition of technical and allocative efficiency, such as Morey, Fine and Loree [12] and Byrnes and Valdmanis [13]. Third, and finally, we note the emergence of more innovative studies that deal with the disposal hull model [14], the congestion DEA model [15], and the output distance function [16].

Pilyavsky et al. [17] analyze Ukrainian hospitals, using a DEA model. Barbeta, Turati and Zago [16] analyze Italian hospitals, using an output distance function and adopting stochastic and DEA approaches. Siciliani [11] analyzes the technical efficiency of Italian hospitals, while Häkkinen [18] analyzes the technical efficiency of the Finnish health care system, using a DEA model. Dismuke and Sena [4] focus on Portuguese hospitals, using a DEA model; and, Hofmarcher, Paterson and Riedel [19] analyze Austrian hospitals, using a DEA model, as well.

Among the studies that employ parametric approaches, we mention Blank and Eggink [20] who analyze the efficiency of Dutch hospitals, using a stochastic frontier model to distinguish between technical and allocative efficiency. Greene [21] analyzes the technical efficiency of US hospitals, focusing on heterogeneity issues. Rosko [22] and Zuckerman et al. [23] adopt a stochastic cost frontier to analyze US hospitals.

\section{Theoretical Background}

Chambers, Chung, and Fare [24-25] propose flexible measures of firm performance, deriving from production theory. They introduced the directional distance function, which, in production theory, is the opposite of Luenberger's benefit function (see Luenberger [26] for a discussion of the benefit function in a consumer context). The directional distance function measures the smallest changes in inputs and outputs in a given direction, which are necessary for a producer to reach the production frontier. The directional distance function determines, thus, a shortcut in one direction, which permits an observed production unit to reach the production frontier. In economic terms, the directional distance function makes it possible to evaluate the scale of the economies that can be achieved and the possible improvements in production; it also provides a benchmark, by defining a reference point to be reached. The principal advantage of the directional distance function lies in its ability to take account, simultaneously, of (variations in) both inputs and outputs. 
Let the technology be described by a set, $T \subseteq R_{+}^{N} \times R_{+}^{M}$, defined by:

$$
T_{t}=\left\{\left(x_{t}, y_{t}\right): x_{t} \text { can produce } y_{t}\right\} \text {, }
$$

where $x_{t} \in R_{+}^{N}$ is a vector of inputs and $y_{t} \in R_{+}^{M}$ is a vector of outputs at the time period $t$. Throughout this paper, technology satisfies the following conventional assumptions:

A1: $(0,0) \in T_{t},\left(0, y_{t}\right) \in T_{t} \Rightarrow y_{t}=0$, i.e., no free lunch;

A2: the set $A\left(x_{t}\right)=\left\{\left(u_{t}, y_{t}\right) \in T_{t} ; u_{t} \leq x_{t}\right\}$ of dominating observations is bounded $\forall x_{t} \in R_{+}^{N}$, i.e., infinite outputs are not allowed with a finite input vector;

A3: $T_{t}$ is closed;

A4: $\forall\left(x_{t}, y_{t}\right) \in T_{t},\left(x_{t},-y_{t}\right) \leq\left(u_{t},-v_{t}\right) \Rightarrow\left(u_{t}, v_{t}\right) \in T_{t}$, i.e., fewer outputs can always be produced with more inputs, and vice versa (strong disposal of inputs and outputs);

A5: $T_{t}$ is convex.

The directional distance function generalizes the traditional Shephard distance function [27]. The directional distance function projects an input and/or output vector from itself to the technology frontier, in a pre-assigned direction. In the case of a radial direction, out of the origin, we retrieve the classical Shephard distance function. We are finally in position to formally define the directional distance function. The function $D_{t}: R^{n+p} \times R^{n+p} \rightarrow R \cup\{-\infty\} \cup\{+\infty\}$ defined by

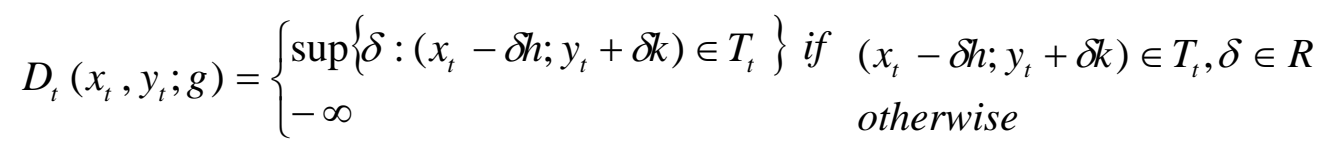

is called the directional distance function in the direction of $g=(h, k)$. To make this approach operational, it is necessary to take an appropriate direction. We do this by considering the direction $g=(x, y)$. In this case, the directional distance function is similar to the proportional distance function introduced by Briec [28]. This distance function is based on simultaneous proportional modifications of inputs and outputs; it generalizes Debreu's [29] and Farrell's [30] measures and is equally straightforward to interpret.

To estimate the proportional distance function, we use a non-parametric approach [31-32] and solve our program using linear programming techniques in Mathematica v. 5.0. The technology can be written as:

$$
T_{t}=\left\{\left(x_{t}, y_{t}\right), x_{t} \geq \sum_{j} \theta_{j} x_{t}^{j}, y_{t} \leq \sum_{j} \theta_{j} y_{t}^{j}, \sum_{j} \theta_{j}=1, \theta_{j} \geq 0, j=1, \ldots, J\right\} .
$$

The linear program that calculates the values of the directional distance function is given by:

$$
\begin{aligned}
& D_{t}\left(x_{t}, y_{t}\right)=\max \delta_{t} \\
& \text { s.t. } x_{t}-\delta_{t} x_{t} \geq \sum_{j} \theta_{j} x_{t}^{j},
\end{aligned}
$$




$$
\begin{aligned}
& y_{t}+\delta_{t} y_{t} \leq \sum_{j} \theta_{j} y_{t}^{j}, \\
& \sum_{j} \theta_{j}=1, \quad j=1 \ldots J .
\end{aligned}
$$

Suppose that an individual hospital is represented by a production vector, $\left(x_{t}, y_{t}\right)$, with corresponding technology $T_{t}$, and, then, the production vector is changed to $\left(x_{t+1}, y_{t+1}\right)$ with corresponding technology $T_{t+1}$. In order to assign a cardinal measure to the productivity change, we can use the directional distance function in one of two ways, using either the initial technology at $t$ or the final technology at $t+1$ as a reference. In this case, the Luenberger productivity indicator proposed by Chambers [29-30] can be employed to evaluate productivity change. The productivity indicator is constructed as the arithmetic mean of the productivity change measured by the technology at $T_{t+1}$ and the productivity change measured by the technology at $T_{t}$.

The Luenberger productivity indicator is defined as:

$$
L\left(z_{t}, z_{t+1}\right)=\frac{1}{2}\left[D_{t+1}\left(z_{t} ; g\right)-D_{t+1}\left(z_{t+1} ; g\right)+D_{t}\left(z_{t} ; g\right)-D_{t}\left(z_{t+1} ; g\right)\right]
$$

where $z_{t}=\left(x_{t}, y_{t}\right)$. Positive productivity growth (decline) is indicated by a positive (negative) value of $L$. Unlike the Malmquist index, the Luenberger productivity indicator is additively decomposed:

$$
\begin{aligned}
L\left(z_{t}, z_{t+1}\right)= & {\left[D_{t}\left(z_{t} ; g\right)-D_{t+1}\left(z_{t+1} ; g\right)\right]+} \\
& \frac{1}{2}\left[D_{t+1}\left(z_{t+1} ; g\right)-D_{t}\left(z_{t+1} ; g\right)+D_{t+1}\left(z_{t} ; g\right)-D\left(z_{t} ; g\right)\right]
\end{aligned}
$$

where the term inside the first brackets measures efficiency change between time periods $t$ and $t+1$, while the arithmetic mean of the difference between the two figures inside the second brackets expresses the technological change component, which represents the shift of technology between the two time periods. This decomposition was inspired by the breakdown of the Malmquist productivity index in Färe et al. [33].

\section{Data and Results}

We compiled our dataset on Portuguese hospitals from the Portuguese Ministry of Health and from the financial accounts of Portuguese hospitals. Our dataset covers the years from 1997 up to 2004 and 51 hospitals - the vast majority of hospitals in Portugal - and, hence, we are left with a balanced panel of 408 observations.

We assume that hospitals produce four outputs: (i) case flows (number of persons that leave the hospital), (ii) length of stay (average number of days a person stays in the hospital), (iii) 
consultations and (iv) emergency cases. Hospitals employ, in turn, three inputs: (vi) number of beds, (vii) personnel and (viii) total variable costs. Table 1 presents descriptive statistics.

$<$ Table 1 here $>$

The Luenberger productivity indicator is calculated using linear programming techniques. Table 2 reports the results. The Luenberger productivity indicator (L) is decomposed into its two constituents: technical-efficiency change (the diffusion or catch-up component - EFFCH), and technological change (the innovation or frontier-shift component - TECH). EFFCH represents the diffusion of best-practice technology in the management of hospitals and it is attributable to, among other factors, technical experience, management and organization. Improvements in technical efficiency denote upgraded organizational factors associated with the use of inputs and outputs, as well as the relationship between inputs and outputs. TECH, in its turn, and to be short, results from the adoption of new technologies by best-practice hospitals and is closely associated with investment.

$<$ Table 2 here $>$

From Table 2 we observe that the productivity change score is mixed for Portuguese hospitals, in the period analyzed. The mean value of L (-5.1\%) is negative, signifying that there was productivity decline during the period analyzed.

The mean value of EFFCH is close to $0(+0.59 \%)$, implying that the average $\mathrm{L}$ score is explained by TECH. In this sense, Portuguese hospitals were very efficient during the period analyzed. Many hospitals represent the production frontier throughout the sample period, achieving, thus, nil EFFCH scores. In such a case, only technological change explains productivity variations. This is of primary interest, and naturally leads to the analysis of the nature of TECH, which can be neutral or biased. In terms of the directional distance function, the nature of TECH has been analyzed recently by Briec et al. [34].

The TECH component is negative on average. Moreover, for the hospitals where productivity increases, it is the technical efficiency component that drives productivity change. Taken at face value, this result suggests that there was low investment in new technologies.

For the sake of exposition, we consider six possible combinations of technical efficiency change and technological change. In particular, the combinations are as follows:

1. Improvements in technical efficiency co-exist with positive technological change. We find no hospitals that meet this criterion, the best possible combination.

2. Positive nil technical efficiency change co-exists with positive technological change. We find 5 hospitals - about $10 \%$ of the total number of hospitals in the sample - in this category.

3. Improvement in technical efficiency co-exists with negative technological change. We find 15 hospitals in this category, or about $30 \%$ of the sample. 
4. Deterioration in technical efficiency co-exists with positive technological change. We find 3 hospitals in this category or about $5 \%$ of the sample.

5. Zero technical efficiency co-exists with negative technological change. There are 15 hospitals in this category, or about $30 \%$ of the sample.

6. Negative technological change co-exists with deterioration in technical efficiency, the worst combination possible. 13 hospitals - about $25 \%$ of the sample - experienced this combination of events.

\section{Conclusion}

This paper analyzed hospital efficiency and productivity growth employing the directional distance function and the Luenberger productivity indicator to study a representative sample of Portuguese hospitals. The results show that the average Portuguese hospital did not experience productivity growth between 1997 and 2004. In particular, no hospital experienced simultaneously improvements in technical efficiency and positive technological change. In addition, only those hospitals with nil technical efficiency change and positive technological change experienced a positive Luenberger productivity indicator, denoting productivity growth. Therefore, there is room to increase both technical efficiency and technological change. In a broad economic sense, technical change (innovation) - the main driver of productivity growth - is related to investment. Capital accumulation, which determines the adoption of technology by best-practice hospitals, thereby shifts the efficiency frontier. This is verified by the fact that there is a positive technological change for only 8 of the 51 hospitals analyzed.

This paper cannot be directly compared with other papers that analyze hospital efficiency and productivity growth, since it uses an innovative approach. However, it should be noted that, in contrast with Hofmarcher et al. [19], our results present higher levels of inefficiency, which may be attributable to the method adopted. Future research ought to consider different time periods and variables in order to allow comparisons across alternative methodologies and to identify investment episodes and policy reforms associated with a given dynamic path of productivity. 


\section{References}

1. Boussemart J, Briec W, Kerstens K, Poutineau J. Luenberger and Malmquist productivity indices: Theoretical comparisons and empirical illustrations. Bulletin of Economic Research 2003; 55: 391-405.

2. Hollingsworth B, Street A. The market for efficiency analysis of health care organisations. Health Economics 2006; 15: 1055-1059.

3. Carreira C. Economias de escala e de gama nos hospitais públicos Portugueses: Uma aplicação da função de custo variável translog. GEMF Discussion Paper, University of Coimbra 1999; 1.

4. Dismuke C, Sena V. Has DRG payment influenced the technical efficiency and productivity of diagnostic technologies in Portuguese public hospitals? An empirical analysis using parametric and non-parametric methods. Health Care Management Science 1999; 2: 107-116.

5. Lima E. A produção e a estrutura de custos dos hospitais públicos: Uma aplicação de um modelo translogaritmico. Associação Portuguesa da Economia da Saúde Discussion Paper 2000; 2 .

6. Ozcan Y, Luke R, Haksever C. Ownership and organizational performance: A comparison of technical efficiencies across hospitals types. Medical Care 1992; 30: 781-84.

7. Valdmanis V. Sensitivity Analysis for DEA models. Journal of Public Economics 1992; 48: 185-205.

8. Burgess J, Wilson D. Technical efficiency in Veterans Administration hospitals. In The Measurement of Productivity Efficiency: Techniques and Applications, Fried H, Lovell C, Schmidt S (eds). Oxford University Press: Oxford, 1993.

9. Dalmau E, Puig-Junoy J. Market structure and hospital efficiency: Evaluating potential effects of deregulation in the National Health Service. Review of Industrial Organization 1998; 13: 447-466.

10. Rodríguez-Álvarez A, Lovell C. Excess capacity and expense preference behaviour in national health systems: An application to the Spanish public hospitals. Health Economics 2004; 13: 157-169.

11. Siciliani L. Estimating technical efficiency in the hospital sector with panel data: A comparison of parametric and non-parametric techniques. Applied Health Economics \& Health Policy 2006; 5: 99-116.

12. Morey R, Fine D, Loree S. Comparing the allocative efficiency of hospitals. International Journal of Management Science 1990; 18: 71-83. 
13. Byrnes V, Valdmanis V. Analysing technical and allocative efficiency of hospitals. In Data Envelopment Analysis: Theory, Methodology and Applications, Charnes A, Cooper W, Lewin A, Seiford L (eds). Kluwer Academic Publishers: Dordrecht, 1994.

14. Beguin C, Simar L. Analysis of the expenses linked to hospital stays: How to detect outliers. Health Care Management Science 2004; 7: 89-96.

15. Ferrier G, Rosko M, Valdmanis V. Analysis of uncompensated hospital care using a DEA model of output congestion. Health Care Management Science 2006; 9: 187-188.

16. Barbeta G, Turati G, Zago A. Behavioural differences between public and private nonprofit hospitals in the Italian Health Service. Health Economics (forthcoming).

17. Pilyavsky A, Aaronson W, Bernet P, Rosko M, Valdmanis V, Golubchikov M. East-west: does it make a difference to hospital efficiencies in Ukraine? Health Economics 2006; 15: 1173-1186.

18. Häkkinen U. The impact of changes in Finland's health care system. Health Economics 2005; 14(S1): S101-S118.

19. Hofmarcher M, Paterson I, Riedel M. Measuring hospital efficiency in Austria: A DEA approach. Health Care Management Science 2002; 5: 7-14.

20. Blank J, Eggink E. The decomposition of cost efficiency: An empirical application of the shadow cost function model to Dutch general hospitals. Health Care Management Science 2004; 7: 79-88.

21. Greene W. Distinguishing between heterogeneity and efficiency: Stochastic frontier analysis of the World Health Organisation's panel data on national health care systems. Health Economics 2004; 13: 959-980.

22. Rosko M. Cost efficiency of US hospitals: a stochastic frontier approach. Health Economics 2001; 10: 539-551.

23. Zuckerman S, Hardley J, Jezzoni L. Measuring hospital efficiency with a cost function. Journal of Health Economics 1994; 13: 255-280.

24. Chambers R. A new look at exact input, output, and productivity measurement. Department of Agricultural and Resource Economics Working Paper, University of Maryland 1996; 96-05.

25. Chambers R. Exact nonradial input, output, and productivity measurement. Economic Theory 2002; 20: 751-765.

26. Luenberger D. Benefit function and duality. Journal of Mathematical Economics 1992; 21: 461-481.

27. Shephard R. Theory of Cost and Production Functions. Princeton University Press, Princeton, 1970.

28. Briec W. A graph type extension of Farrell technical efficiency measure. Journal of Productivity Analysis 1997; 8: 95-110. 
29. Debreu G. The coefficient of resource utilization. Econometrica 1951; 19: 273-292.

30. Farrell M. The measurement of productive efficiency. Journal of the Royal Statistical Society 1957; 120: 253-281.

31. Banker R, Maindiratta A. Nonparametric analysis of technical and allocative efficiency in production. Econometrica 1988; 56: 1315-1332.

32. Varian H. The nonparametric approach to production analysis. Econometrica 1984; 52: 579-597.

33. Färe R, Grosskopf S, Lindgren B, Roos P. Productivity developments in Swedish hospitals: a Malmquist output index approach. In Data Envelopment Analysis: Theory, Methodology and Applications, Charnes A, Cooper V, Lewin A, Seiford L (eds). Kluwer Academic Publishers: Dordrecht, 1989.

34. Briec W, Chambers R, Färe R, Peypoch N. Parallel neutrality. Journal of Economics 2006; 88: 285-305. 
Table 1. Descriptive Statistics 1997-2004

\begin{tabular}{lcccc}
\hline Variables & Minimum & Maximum & Mean & Stand. Dev. \\
Outputs: & & & & \\
$\quad$ Case flows & 2310 & 24547 & 10841 & 5561 \\
Length of stay & 4 & 13 & 7 & 1 \\
$\quad$ Consultations & 13459 & 284276 & 76698 & 48195 \\
$\quad$ Emergency cases & 0 & 217603 & 88340 & 42668 \\
& & & & \\
Inputs: & 66 & 661 & 294 & 148 \\
$\quad$ Beds & 213 & 2698 & 991 & 574 \\
Personnel & 6678855 & 123812767 & 39444716 & 26034611 \\
Variable costs (real; $€$ ) & & & & \\
\hline
\end{tabular}


Table 2. Productivity Changes in Hospitals ranked according to the Luenberger Indicator (1997-2004)

\begin{tabular}{|c|c|c|c|c|c|c|c|}
\hline N. Hospital & EFFCH & TECH & $\mathrm{L}$ & N. Hospital & EFFCH & TECH & $\mathrm{L}$ \\
\hline 1 CH Vila Nova de Gaia & 0.000 & 0.160 & 0.160 & 27 H Viseu & 0.000 & -0.057 & -0.057 \\
\hline 2 CH Coimbra & 0.000 & 0.102 & 0.102 & 28 H Angra do Heroísmo & 0.003 & -0.061 & -0.058 \\
\hline 3 H Almada & -0.029 & 0.108 & 0.079 & 29 H Vale do Sousa & 0.000 & -0.065 & -0.065 \\
\hline 4 H Portalegre & 0.102 & -0.048 & 0.054 & $30 \mathrm{H}$ Chaves & 0.090 & -0.160 & -0.070 \\
\hline 5 H Amarante & 0.086 & -0.039 & 0.047 & 31 H Horta & -0.033 & -0.037 & -0.070 \\
\hline 6 H Egas Moniz & 0.000 & 0.042 & 0.042 & 32 CH Médio Tejo & 0.000 & -0.070 & -0.070 \\
\hline 7 H Évora & 0.036 & -0.009 & 0.027 & 33 H Elvas & 0.107 & -0.179 & -0.072 \\
\hline 8 H Faro & 0.022 & -0.001 & 0.021 & 34 H Aveiro & 0.018 & -0.092 & -0.074 \\
\hline 9 CH Alto Minho & 0.022 & -0.009 & 0.013 & 35 H Leiria & 0.000 & -0.074 & -0.074 \\
\hline 10 H Santa Maria da Feira & 0.000 & 0.011 & 0.011 & 36 H V. F. de Xira & -0.005 & -0.082 & -0.087 \\
\hline 11 H Bragança & 0.105 & -0.099 & 0.006 & 37 H Famalicão & -0.019 & -0.073 & -0.092 \\
\hline 12 H Braga & 0.000 & 0.006 & 0.006 & 38 CH Baixo Alentejo & 0.004 & -0.103 & -0.099 \\
\hline 13 H Pulido Valente & 0.047 & -0.047 & 0.000 & 39 CH Barlavento Algarvio & -0.034 & -0.081 & -0.115 \\
\hline 14 H Figueira da Foz & -0.028 & 0.023 & -0.005 & 40 H S. Francisco Xavier & -0.070 & -0.048 & -0.118 \\
\hline 15 CH Caldas da Rainha & 0.080 & -0.086 & -0.006 & 41 H Oliveira de Azeméis & 0.000 & -0.136 & -0.136 \\
\hline 16 H Divino Espírito Santo & 0.019 & -0.026 & -0.007 & 42 H Ovar & 0.000 & -0.136 & -0.136 \\
\hline 17 H Mirandela & -0.035 & 0.022 & -0.013 & $43 \mathrm{CH}$ Vila do Conde & 0.000 & -0.138 & -0.138 \\
\hline 18 H Santo Tirso & 0.000 & -0.015 & -0.015 & 44 H Guarda & -0.013 & -0.126 & -0.139 \\
\hline 19 H Guimarães & 0.000 & -0.016 & -0.016 & 45 CH Cova da Beira & -0.004 & -0.139 & -0.143 \\
\hline 20 H Setúbal & -0.001 & -0.021 & -0.022 & 46 H Castelo Branco & -0.057 & -0.092 & -0.149 \\
\hline 21 H Santarém & 0.048 & -0.073 & -0.025 & 47 H Barcelos & -0.014 & -0.137 & -0.151 \\
\hline 22 CH Cascais & 0.000 & -0.027 & -0.027 & 48 H Lamego & 0.000 & -0.154 & -0.154 \\
\hline 23 H Barreiro & -0.017 & -0.013 & -0.030 & 49 H Águeda & 0.000 & -0.164 & -0.164 \\
\hline 24 H São João da Madeira & 0.000 & -0.035 & -0.035 & 50 H Montijo & 0.000 & -0.193 & -0.193 \\
\hline 25 H Curry Cabral & 0.000 & -0.047 & -0.047 & $51 \mathrm{CH}$ Torres Vedras & -0.092 & -0.127 & -0.219 \\
\hline 26 Vila Real Peso da Régua & -0.037 & -0.018 & -0.055 & & & & \\
\hline \multicolumn{8}{|l|}{ Summary statistics: } \\
\hline Mean & 0.006 & -0.056 & -0.051 & & & & \\
\hline Median & 0.000 & -0.057 & -0.055 & & & & \\
\hline St. Dev. & 0.041 & 0.073 & 0.078 & & & & \\
\hline
\end{tabular}

